Article

\title{
Geologic Mapping and Age Determinations of Tsiolkovskiy Crater
}

\author{
Gloria Tognon ${ }^{1,2, *(\mathbb{D})}$, Riccardo Pozzobon ${ }^{2,3}$, Matteo Massironi ${ }^{1,2,3}$ (D) and Sabrina Ferrari ${ }^{1}$ \\ 1 Centro di Ateneo di Studi e Attività Spaziali “G. Colombo", Università degli Studi di Padova, 35131 Padova, \\ Italy; matteo.massironi@unipd.it (M.M.); sabrina.ferrari@unipd.it (S.F.) \\ 2 INAF, Osservatorio Astronomico di Padova, 35122 Padova, Italy; riccardo.pozzobon@unipd.it \\ 3 Dipartimento di Geoscienze, Università degli Studi di Padova, 35131 Padova, Italy \\ * Correspondence: tognon.glo@gmail.com
}

check for updates

Citation: Tognon, G.; Pozzobon, R.; Massironi, M.; Ferrari, S. Geologic Mapping and Age Determinations of Tsiolkovskiy Crater. Remote Sens. 2021, 13, 3619. https://doi.org/ $10.3390 /$ rs13183619

Academic Editors: Stephan Van Gasselt and Andrea Nass

Received: 11 July 2021

Accepted: 6 September 2021

Published: 10 September 2021

Publisher's Note: MDPI stays neutral with regard to jurisdictional claims in published maps and institutional affiliations.

Copyright: (c) 2021 by the authors. Licensee MDPI, Basel, Switzerland. This article is an open access article distributed under the terms and conditions of the Creative Commons Attribution (CC BY) license (https:/ / creativecommons.org/licenses/by/ $4.0 /)$.

\begin{abstract}
Tsiolkovskiy is a $\sim 200 \mathrm{~km}$ diameter crater presenting one of the few mare deposits of the lunar far side. In this work, we perform a geological study of the crater by means of morphostratigraphic and color-based spectral mappings, and a detailed crater counting age determination. The work aims at characterizing the surface morphology and compositional variation observed from orbital data including the Lunar Reconnaissance Orbiter Wide Angle Camera and Clementine UVVIS Warped Color Ratio mosaics, and attempts a reconstruction of the evolutionary history of the Tsiolkovskiy crater through both relative and absolute model age determinations. The results show a clear correlation between the geologic and spectral units and an asymmetric distribution of these units reflecting the oblique impact origin of the crater. Crater counts performed using the spectral units identified on the smooth crater floor returned distinct age ranges, suggesting the occurrence of at least three different igneous events, generating units characterized by particular compositions and/or degree of maturity. This work demonstrates the scientific value of Tsiolkovskiy crater for a better understanding of the volcanic evolution of the Moon and, in particular, of its far side.
\end{abstract}

Keywords: geologic mapping; Tsiolkovskiy; moon; morphology; crater size-frequency distributions (CSFDs); stratigraphy

\section{Introduction}

Among the main scientific goals and priorities for lunar exploration is an understanding of the thermal and compositional evolution of the Moon [1]. It is of pivotal importance to determine whether the composition of the lunar mantle is uniform from the near side to the far, and to establish the chemical evolution of magmas and the evolution of magma production rates over time.

It is thus necessary to collect samples of basalts from the less explored lunar far side, to investigate the subsurface with active subsurface sounding techniques, and to deploy a geophysical network for profiling the Moon's internal structure [1].

In this work, we focused our attention on a mare flooded crater located on the lunar far side: the Tsiolkovskiy crater. This crater presents a pristine and particularly smooth resurfaced floor that allows us to obtain a perspective on the evolution of lunar magmatism on the far side.

The Tsiolkovskiy crater could help to answer the still open questions related to the sparse distribution of far side volcanic maria, the control exerted by the lunar crust and mantle on magma genesis and transport, as well as the vertical and lateral variability of the thickness and bulk composition of the lunar maria, crust, and mantle.

Previous regional maps produced of the Tsiolkovskiy crater were based on low resolution photographs and images taken by the crew of the Apollo 15 mission [2] and by the Lunar Orbiter 3 spacecraft [3,4]. The first unified 1:5 M scale global geologic map of the Moon was published only recently [5], produced by merging and redrafting the six 
previous lunar geologic maps for the near [6], east [7], west [8], central far [9], north [10], and south [11] sides. This map, however, discriminates only the ejecta deposits and the basaltic infilling of the Tsiolkovskiy crater. A more detailed morphologic mapping, enabling the distinction of four geologic units and five facies of ejecta, was presented by [12] However, this mapping does not discriminate morphologic and tectonic features, nor different crater rim units. Last but not least, none of the previous mappings took into consideration the color variations of the surface as seen from color basemaps.

Therefore, we performed a more comprehensive geological interpretation of the Tsiolkovskiy crater by means of a morpho-stratigraphic and color-based spectral mapping coupled with age determinations, aimed at understanding the geologic evolution of the area over time, highlighting the scientific significance of this crater.

\section{Geologic Background of the Tsiolkovskiy Crater}

The Tsiolkovskiy crater is a $\sim 200 \mathrm{~km}$ diameter complex crater located at $20.4^{\circ} \mathrm{S}, 129.1^{\circ}$ E. With its approximately $12,000 \mathrm{~km}^{2}$ basaltic floor, it stands out in being one of the few mare exposures of the lunar far side. The crater presents an irregular shape, as do its ejecta deposits. The uneven ejecta distribution reflects the origin of Tsiolkovskiy through an oblique impact in the NW-SE direction [13]. In particular, evidence of this asymmetry lies in an ejecta forbidden zone extending outside the NW outer rim, and indicating an impact angle of $<45^{\circ}$ with an azimuth of $\sim 315^{\circ}$, and a shortened ejecta blanket marked by lobate margins in the SE direction [12].

Moreover, the formation of the Tsiolkovskiy crater is responsible for the generation of an apparently unique long runout landslide on the Moon, formed soon after the crater impact on its western rim [14]. The collapse of the crater rim led to an encroachment into the adjacent Pre-Nectarian, un-flooded, Fermi crater by the $\sim 72 \mathrm{~km}$ long runout landslide, marked by lobes and parallel flow lines, which covered most of the Fermi crater floor (Figure 1).



Figure 1. Structure of Tsiolkovskiy (on the right) superposing on the $\sim 230 \mathrm{~km}$ diameter Fermi crater (on the left). The white dashed circle identifies the approximate rim of Fermi; the black dashed and dotted line delimits Tsiolkovskiy's landslide, modified from [14]; the blue arrow indicates the impact direction for Tsiolkovskiy. 
In contrast to the fate of Fermi, Tsiolkovskiy was not affected by impacts of younger Eratosthenian nor Copernican craters and related ejecta rays. Thus, it still preserves a clear and pristine morphology. From the remarkable flat smooth floor, a $\sim 6.5 \mathrm{~km}$ high well-preserved central peak formed by the rebound of the crust during the impact clearly stands out with respect to the dark color of the surrounding mare. A slightly uprange offset of the central peak itself is yet more evidence for the oblique origin of the crater [15]. The large size of Tsiolkovskiy and the height of its central peak, moreover, would suggest that the impact leading to the formation of this crater could have exhumed materials from the lower crust [16] or even from the upper mantle.

The mare deposit, of which the average thickness is calculated to be about $116 \mathrm{~m} \mathrm{[4]}$, is thought to be the result of several small eruptive events [17] that has produced a difference in the present crater floor elevation of more than $450 \mathrm{~m}$, higher in the NW sector and lower in the SE one $[13,18]$. Furthermore, the low-reflectance mare is characterized by slightly different reflectance values possibly indicating distinct lava flows with different chemical compositions and/or ages.

In terms of composition, more detailed information is discernible from the Clementine UVVIS Color Ratio mosaic [19]. Even at first glance, it is possible to appreciate the high color variegation of Tsiolkovskiy with respect to the surrounding highland crust. As observed from the multispectral analysis made by [16], the impact of Tsiolkovskiy led to the excavation of large amounts of anorthosites and norites mixed with highland soil along the crater rim. A more varied composition, additionally including the presence of troctolites [20], characterizes the central peak of the crater on which purest anorthosite [21,22], composed of nearly $100 \%$ anorthite, and olivine $[23,24]$ have been detected. The peculiarity of this crater, however, is the basaltic mare material covering the crater floor which, despite its particularly dark color, is not as rich in $\mathrm{TiO}_{2}$ as the mare exposures on the nearside [25].

Recent crater counts performed on the ejecta and landslide deposits of Tsiolkovskiy have determined a formation age of $3.55 \pm 0.1 \mathrm{Ga}$ [14], similarly to the Upper or Late Imbrian ages inferred by $[2,7,26]$. A lower limit age of 3.2-3.3 Ga [27-29] was, in contrast, derived from crater counting areas defined on the mare deposit.

\section{Datasets and Methods}

\subsection{Basemaps}

In the present work we produced two different maps: a morpho-stratigraphic map, derived from photo-geological interpretation, and a color-based spectral map, derived by associating compositional variations with identified morphological units.

The morpho-stratigraphic mapping was realized on the basis of the Lunar Reconnaissance Orbiter Wide Angle Camera (LROC-WAC) [30] monochrome global mosaic, which has a mean resolution of $\sim 100 \mathrm{~m} /$ pixel (Figure 2a). In order to discriminate small morphological features, in particular on the flat, dark, and shadow-less crater floor, a higher resolution mosaic produced using $\sim 10 \mathrm{~m} /$ pixel images from the Kaguya Terrain Camera (TC) [31] (Figure 2c) was used in support of the LROC-WAC mosaic. An even higher resolution mosaic produced using Lunar Reconnaissance Orbiter Narrow Angle Camera (LROC-NAC) [30] images covering the entire crater would have been too large to be easily managed.

The panchromatic imagery was coupled with the topographic data derived from the merging of data from the Lunar Orbiter Laser Altimeter (LOLA) [32] and Kaguya TC Digital Elevation Model (DEM) [33] with a horizontal and vertical resolution of $\sim 59 \mathrm{~m} /$ pixel and 3-4 m, respectively (Figure 2d). From the elevation data, we derived a topographic hillshade, with default azimuth of $315^{\circ}$ and altitude of $45^{\circ}$, and we generated a surface slope map to discriminate surfaces within defined steepness thresholds, ranging from high $\left(>40^{\circ}\right)$ to low $\left(<15^{\circ}\right)$ (Figure $\left.2 \mathrm{e}-\mathrm{f}\right)$. 


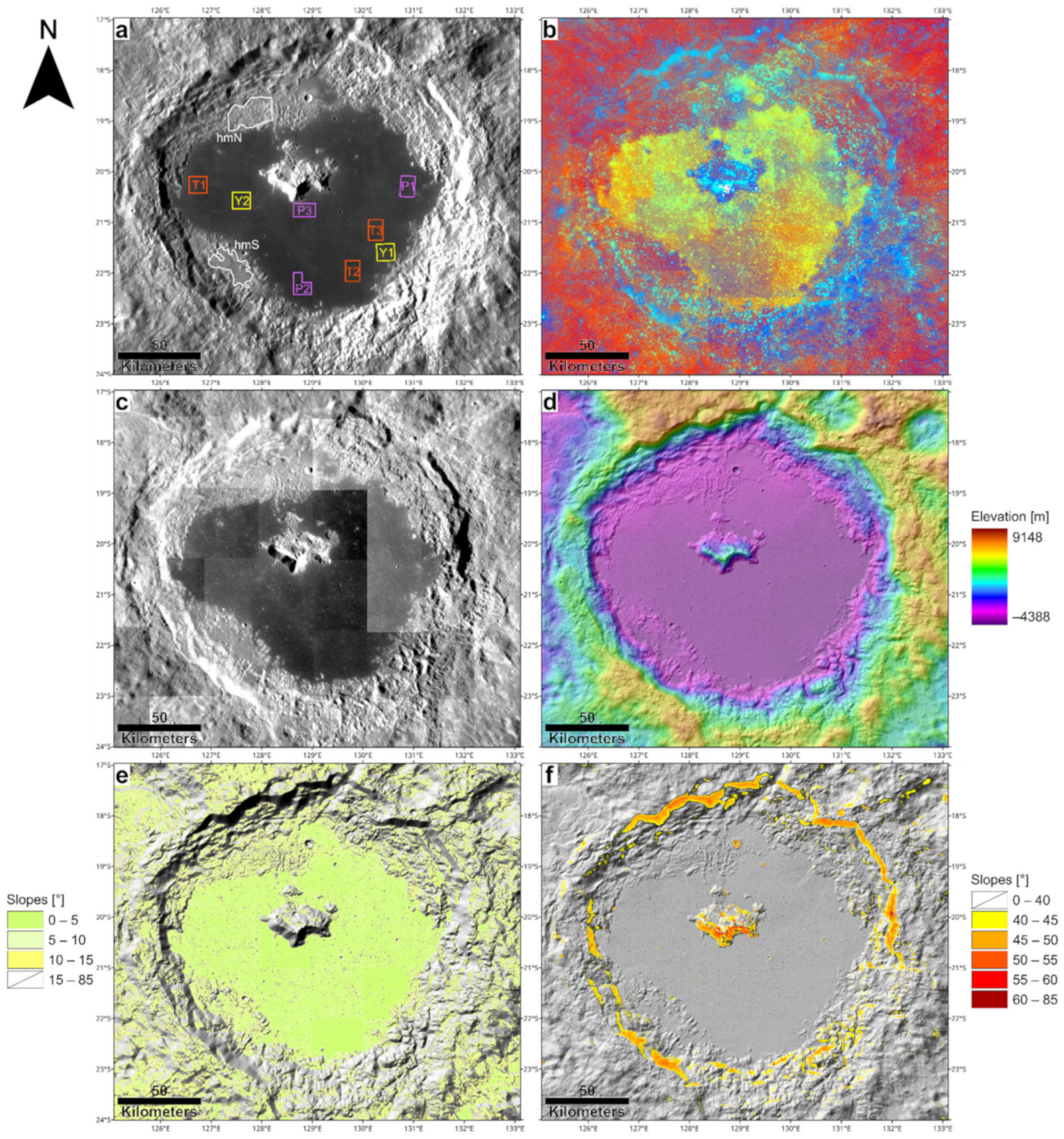

Figure 2. The lunar far side Tsiolkovskiy crater in equirectangular projection. (a) Lunar Reconnaissance Orbiter Wide Angle Camera mosaic ( 100 m/pixel) [30] with boxes delimiting the crater size-frequency distribution measurements areas; (b) Clementine UVVIS Warped Color Ratio mosaic ( 200 m/pixel) [19]; (c) Kaguya Terrain Camera mosaic ( 10 m/pixel) [31]; (d) Lunar Orbiter Laser Altimeter and Kaguya Terrain Camera DEM merge ( 59 m/pixel and 3-4 m) [33] on top of the hillshade DEM-derived basemap; (e) surface slope map for slopes $<15^{\circ}$ on top of the hillshade DEM-derived basemap; and (f) surface slope map for slopes $>40^{\circ}$ on top of the hillshade DEM-derived basemap.

The color-based spectral mapping was produced using the $\sim 200 \mathrm{~m} /$ pixel Clementine UVVIS Warped Color Ratio mosaic (Red: 750/415 nm; Green: 750/1000 nm; and Blue: 415/750 nm, Figure 2b). According to [19], red colors are ascribable to low titanium or high glass contents, and thus also to pyroclastic deposits. High iron contents and 
mafic minerals, in contrast, are represented by green colors. The combination of the presence of mafic minerals and agglutinitic glass-like coatings due to maturation processes is shown by yellow-green colors. Finally, blue colors represent high titanium contents and bright albedos.

The LROC-WAC and Clementine mosaics and the DEM merge basemap were downloaded from the USGS Astrogeology Science Center website, whereas the TC images were downloaded from the SELENE Data Archive.

\subsection{Mapping Technique}

The morpho-stratigraphic and color-based spectral mapping were performed in the Esri ArcGIS 10.4.1 software. The two mappings were carried out in equirectangular projection using the D_MOON datum. Due to their different basemap resolutions, the mapping scales were set to 1:200,000 and 1:400,000 for the morpho-stratigraphic and spectral mapping, respectively, following the rule defined by [34] according to which the mapping scale is set out from the equation:

$$
S_{m}=R_{r} \times 2000
$$

where $S_{m}$ is the mapping scale and $R_{r}$ is the raster resolution.

A dedicated geodatabase was assembled to enable the distinction of linear features, such as contacts, morphologies, and structures, and polygonal vector files were used to represent the geological units. Firstly, we defined the geomorphological features and structures. Then, we delineated certain and approximate contacts for the units. Finally, the polygonal geologic units were generated on the basis of the geologic contacts. Figure 3 shows steps leading to the production of the morpho-stratigraphic map, up to the definition of the color map units, while Figure 4 shows the steps leading to the realization of the color-based spectral map. 

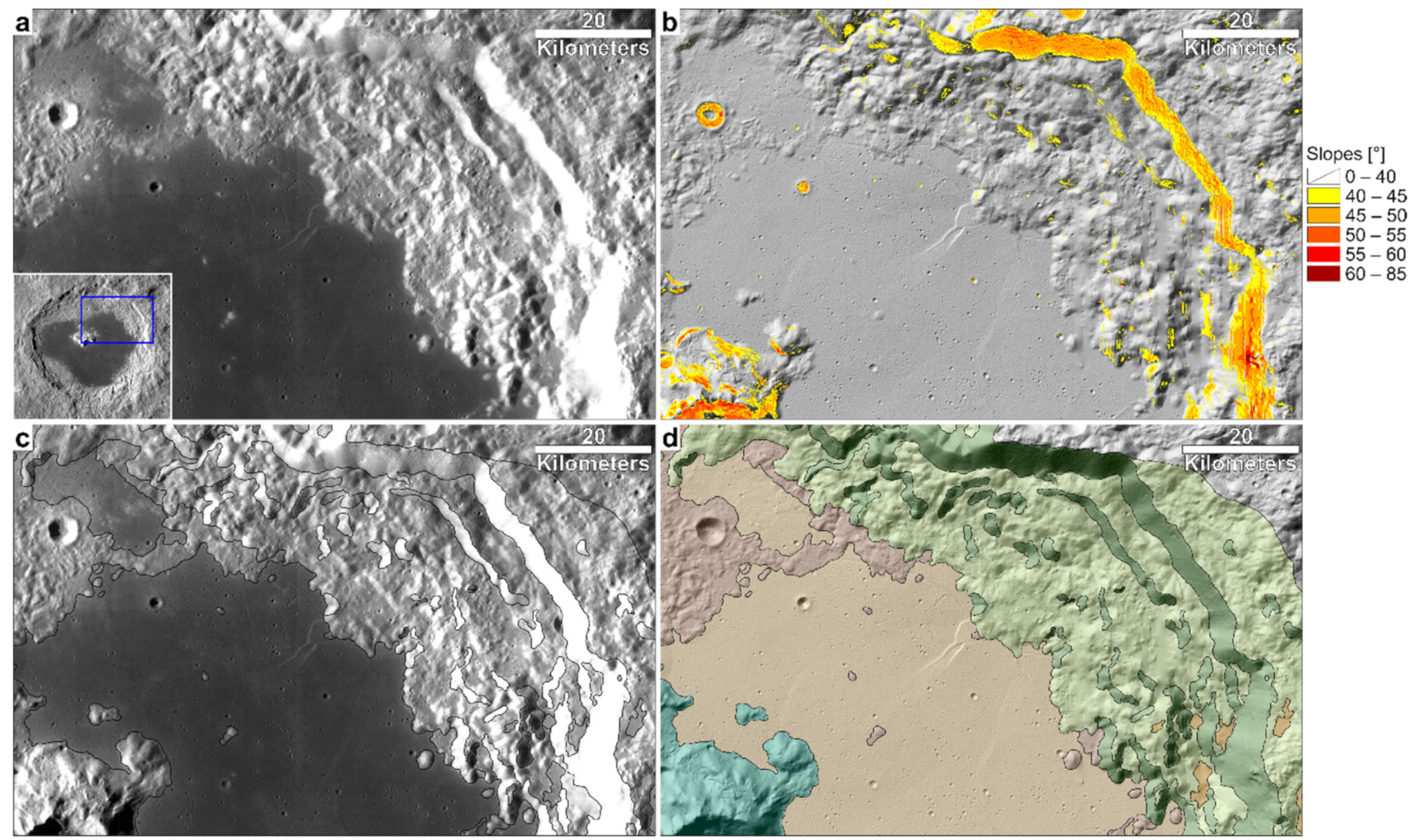

Figure 3. Detailed view of the NE portion of the Tsiolkovskiy crater. (a) Lunar Reconnaissance Orbiter Wide Angle Camera (LROC-WAC) mosaic [30]; (b) DEM-derived hillshade superimposed by the surface slope map highlighting scarps with slopes $>40^{\circ}$; (c) LROC-WAC basemap with geologic contact linework; and (d) geologic units on top of the DEM-derived hillshade.

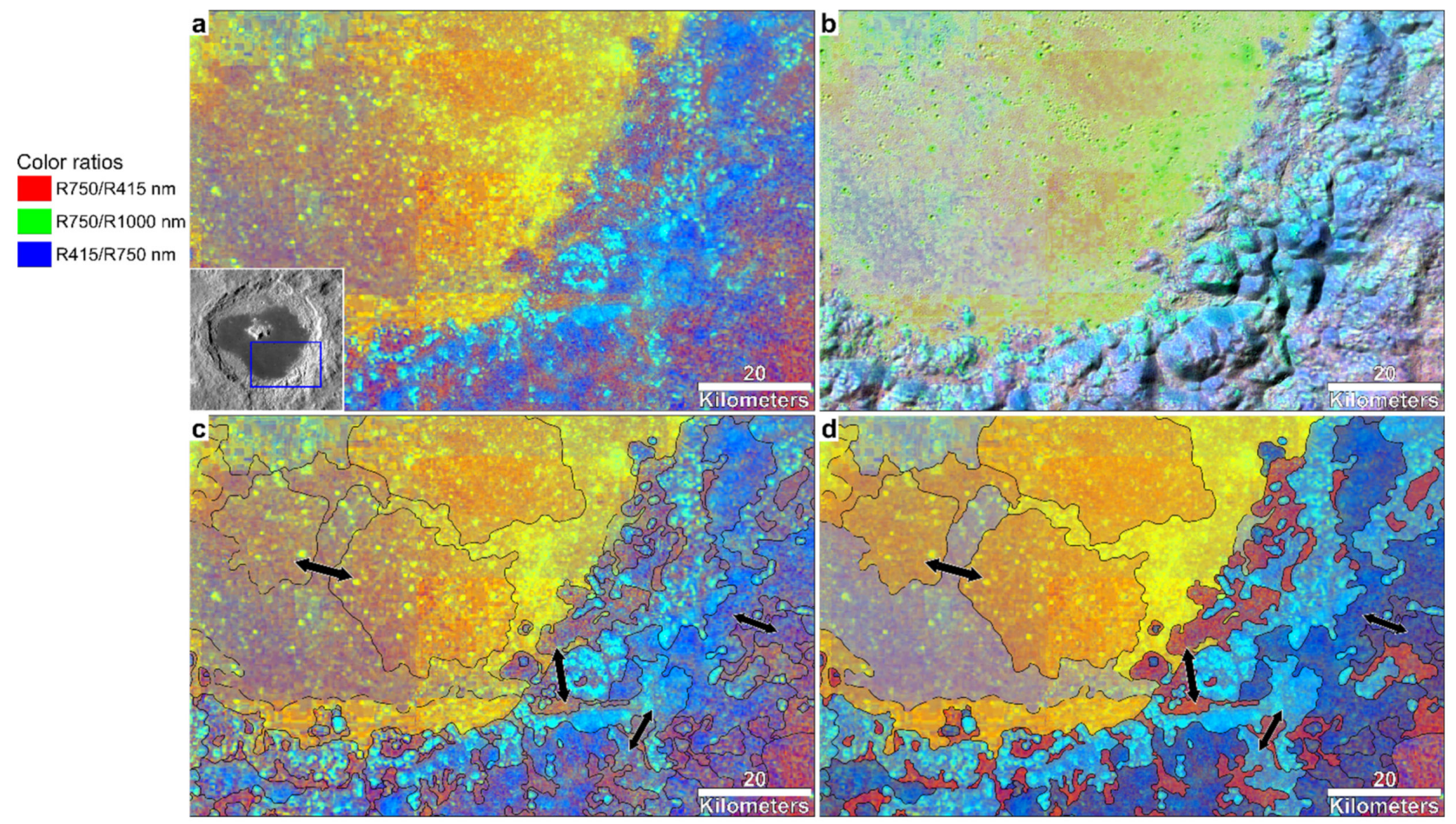

Figure 4. Detailed view of the SE portion of the Tsiolkovskiy crater. (a) Clementine UVVIS Warped Color Ratio mosaic [19]; (b) RGB-IHS pan-sharpening transformation of (a); (c) same as (a) with contact linework; and (d) color-based spectral map. The double black arrows indicate equivalent spectral units showing characteristic combinations of color shades. 
The final output scale was defined according to the USGS recommendations [35], which suggest using a scale $\mathrm{n}$ times larger than the mapping scale following the equation:

$$
\mathrm{SO}_{\mathrm{n}}=\mathrm{S}_{\mathrm{m}} \times \mathrm{n}
$$

where $\mathrm{So}_{\mathrm{n}}$ is the recommended output scale and $\mathrm{n}$ ranges between 2 and 5 . To achieve the best and clearest result we chose an $n$ of 5, obtaining a final output scale of 1:1,000,000 and $1: 2,000,000$ for the morpho-stratigraphic and color-based spectral maps, respectively.

The GIS project for both maps, with related basemaps and mapping shapefiles, is available in the Supplementary Materials.

\subsection{Age Measurements}

As a last step, we performed crater size-frequency distribution (CSFD) measurements to determine the formation age of Tsiolkovskiy and the absolute stratigraphy of the different crater floor units which had been identified by the color-based spectral mapping.

The CSFDs were carried out on LROC-NAC [30] images with resolutions between 0.61 and $1.53 \mathrm{~m} /$ pixel (Appendix A) downloaded from the PILOT (Planetary Image Locator Tool from USGS) data portal.

The crater counts were performed on several areas of about $100 \mathrm{~km}^{2}$ using the CraterTools add-on [36] for the Esri ArcGIS software and exported as a Spatial Crater Count (.scc) summary file. The summary files for all areas are available in the Supplementary Materials.

The exported data were then plotted in the Craterstats2 software [37] using pseudo-log binning [38] and references therein on cumulative plots and fitted with the [39] production and chronology functions. A randomness analysis [40] performed by means of the Mean 2nd-Closest Neighbour Distance (M2CND) measurement was used to verify the homogeneity of the crater population and, eventually, to exclude spatially non-random craters.

\section{Results}

\subsection{Morpho-Stratigraphic Map and Formation Age for the Tsiolkovskiy Crater}

The crater rim of the Tsiolkovskiy crater delimits the mapping area.

The morphology of this complex crater allowed to distinguish three main units on the crater floor and three more units on the crater walls. The stratigraphic correlations between the different geologic units were inferred determining their relative age by observing morphological evidence.

Here follows a brief description of the geologic units associated with unit labels enlisted in stratigraphic order.

1. sm-(floor unit) smooth material: particularly horizontal (mostly $<10^{\circ}$ ) and dark mare deposit punctured by minor impacts rarely reaching $5 \mathrm{~km}$ in diameter; this smooth material presents sharp boundaries with respect to adjacent materials and scattered wrinkle ridges and mare rilles.

2. hm-(floor unit) hummocky material: pre-mare material presenting rolling areas and high-standing bulges characterized by rough material reworked during the impact and debris collapsed from the crater walls.

3. $\quad \mathrm{cp}$-(floor unit) central peak: exclusively well-preserved and bright central peak morphology rising about $6.5 \mathrm{~km}$ above the crater floor.

4. $\mathrm{sp-(wall} \mathrm{unit)} \mathrm{smooth} \mathrm{ponds:} \mathrm{smooth} \mathrm{areas} \mathrm{interpreted} \mathrm{as} \mathrm{melt} \mathrm{ponds} \mathrm{texturally}$ contrasting with the surrounding steep and rough areas.

5. ss-(wall unit) steep scarps: exposed steep scarps (collapsed deposits were not included) with slopes $>40^{\circ}$.

6. is-(wall unit) inner slope: terraces and scarps $<40^{\circ}$ generated by the inward collapse of the crater inner slope during the modification stage.

The northern side of the crater floor is marked by several mare rilles, reaching up to $16.14 \mathrm{~km}$ of length and mostly trending in the NNW-SSE direction. In terms of deformations and faulting, the crater inner walls exhibit many concentric normal faults, whereas 
the crater floor is characterized by several wrinkle ridges, mostly arranged radially to the central peak.

The morpho-stratigraphic map is shown in Figure 5 on top of the DEM-derived hillshade basemap.

The CSFD measurements for determining the formation age of Tsiolkovskiy were performed on hummocky areas located to the NW and SW of the mare infilling (white polygons on Figure 2a) over an area of $\sim 615 \mathrm{~km}^{2}$ (Table 1). The results indicate a Late Imbrian age of $\sim 3.6 \mathrm{Ga}$ for the Tsiolkovskiy crater (Figure 6 and Table 1). 


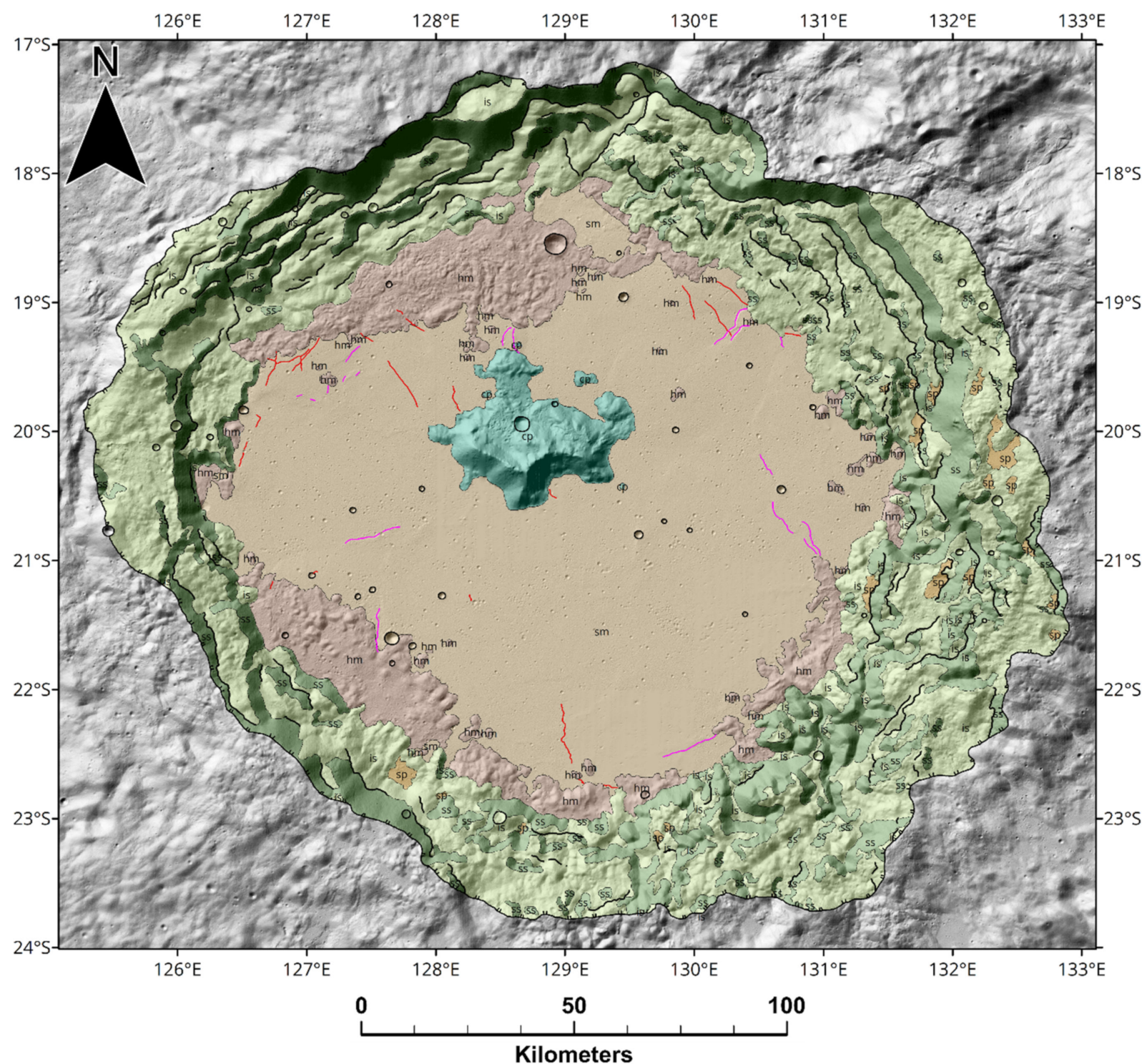

\section{Geologic units}

Crater floor units

sm

sm

$\mathrm{hm}$

Hummocky material

Central peak

Crater wall units

$\mathrm{sp}$

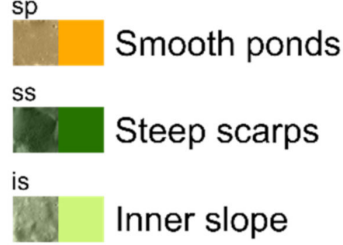

\section{Geologic contacts}

Contact, certain

\section{Linear features}

Crest of small crater rim (diam.>1 km)

Crest of crater rim (diam.> $20 \mathrm{~km}$ )

Mare rille

\section{Tectonic features}

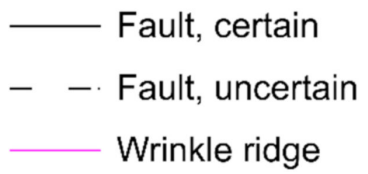

Figure 5. Morpho-stratigraphic map of Tsiolkovskiy visualized on top of the DEM-derived hillshade. Refer to the text for unit descriptions. 
Table 1. The first column repeats the names of the areas considered for the crater size-frequency distribution (CSFD) measurements. The area locations are visible in Figure 2a. The second, third, and fourth columns contain the surface extent of each area, the number of craters selected as standard and as marked (e.g., irregular craters, possible secondary craters, or possible clusters of craters). The fifth, sixth, and seventh columns contain the diameter range of the selected craters and the relative age with correlated errors as from Craterstats2 [37].

\begin{tabular}{|c|c|c|c|c|c|c|}
\hline Area Name & $\begin{array}{c}\text { Area } \\
\left(\mathbf{k m}^{2}\right)\end{array}$ & $\begin{array}{l}\text { No. of } \\
\text { Standard } \\
\text { Craters }\end{array}$ & $\begin{array}{l}\text { No. of Marked } \\
\text { Craters }\end{array}$ & $\begin{array}{l}\text { Fit Diameter } \\
\text { Range } \\
\text { (m) }\end{array}$ & $\begin{array}{c}\text { Relative Age } \\
\text { (Ga) }\end{array}$ & $\begin{array}{c}\text { Relative Age } \\
\text { Errors } \\
\text { (Ga) }\end{array}$ \\
\hline $\mathrm{hmN}$ & 354.44 & 406 & 90 & $60-1300$ & 3.57 & $\begin{array}{l}+0.03 \\
-0.04\end{array}$ \\
\hline hmS & 260.55 & 392 & 107 & $4-1100$ & 3.61 & $\begin{array}{l}+0.03 \\
-0.03\end{array}$ \\
\hline $\mathrm{T} 1$ & 100.00 & 325 & 14 & $4-800$ & 2.98 & $\begin{array}{l}+0.24 \\
-0.44\end{array}$ \\
\hline $\mathrm{T} 2$ & 99.30 & 413 & 32 & $4-800$ & 2.97 & $\begin{array}{l}+0.18 \\
-0.28\end{array}$ \\
\hline T3 & 99.30 & 361 & 81 & 5-1000 & 2.88 & $\begin{array}{l}+0.15 \\
-0.18\end{array}$ \\
\hline P1 & 99.30 & 447 & 104 & $4-700$ & 3.32 & $\begin{array}{l}+0.06 \\
-0.09\end{array}$ \\
\hline P2 & 99.99 & 460 & 175 & $4-700$ & 3.47 & $\begin{array}{l}+0.03 \\
-0.04\end{array}$ \\
\hline P3 & 100.00 & 437 & 38 & $5-800$ & 3.46 & $\begin{array}{l}+0.03 \\
-0.04\end{array}$ \\
\hline Y1 & 100.00 & 299 & 118 & 5-900 & 3.57 & $\begin{array}{l}+0.02 \\
-0.02\end{array}$ \\
\hline $\mathrm{Y} 2$ & 100.00 & 431 & 122 & $4-800$ & 3.57 & $\begin{array}{l}+0.02 \\
-0.02\end{array}$ \\
\hline
\end{tabular}
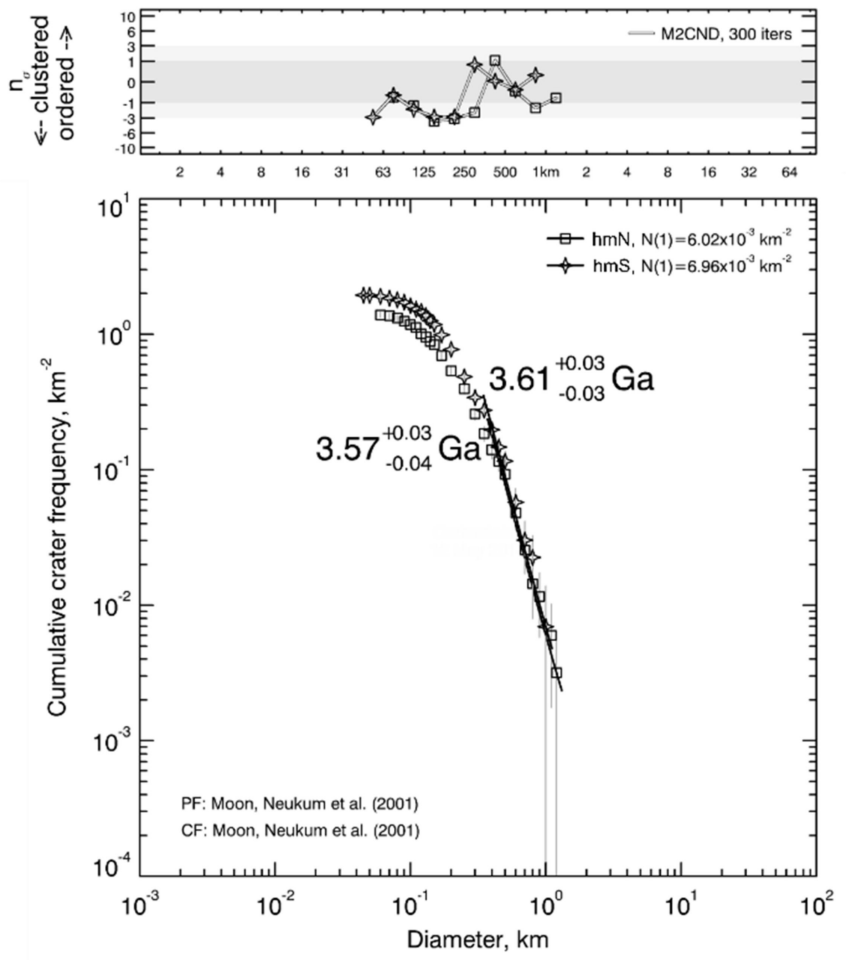

Figure 6. Crater size-frequency distribution (CSFD) measurements performed on hummocky areas for determining the formation age of Tsiolkovskiy. The randomness analysis results are shown in the panel above the CSFDs. 


\subsection{Color-Based Spectral Map and Age Determinations for the Crater Floor}

The color-based spectral mapping was performed on the basis of the color variation as from the Clementine UVVIS Color Ratio mosaic (Figure 2b). The different colors of the units can be linked to the different degrees of maturity and/or composition of the materials [19].

In this case, color variegation led to us to identify and delimit different units showing different hues of the same color. However, due to the low resolution of the basemap there was insufficient confidence for constructing fully independent units and, thus, each color unit groups, within it, different shades of the same color (Figure $4 \mathrm{c}-\mathrm{d}$ ).

In order to discriminate possible age differences related to distinct eruptive events, and eventually determine their absolute stratigraphic relationships, we defined several areas on the crater floor units identified by the color-based spectral linework mapping for measuring the CSFDs.

In particular, we selected three areas inside the purple-blue color units (Figure 2a purple-blue polygons), three areas in the orange color units (Figure 2a orange polygons) and two areas inside the yellow color units (Figure 2a yellow polygons) covering an area of about $100 \mathrm{~km}^{2}$ each (Table 1 ).

Figure 7 and Table 1 show the age results. In particular, the orange color unit stands out as the youngest basaltic unit with an average age of $2.94 \mathrm{Ga}$, followed by the $3.42 \mathrm{Ga}$ intermediate purple-blue color unit. Conversely, the yellow color unit shows similar age results to the formation age of the Tsiolkovskiy crater itself, and thus emerges as the oldest crater floor unit with an age of $3.57 \mathrm{Ga}$. 

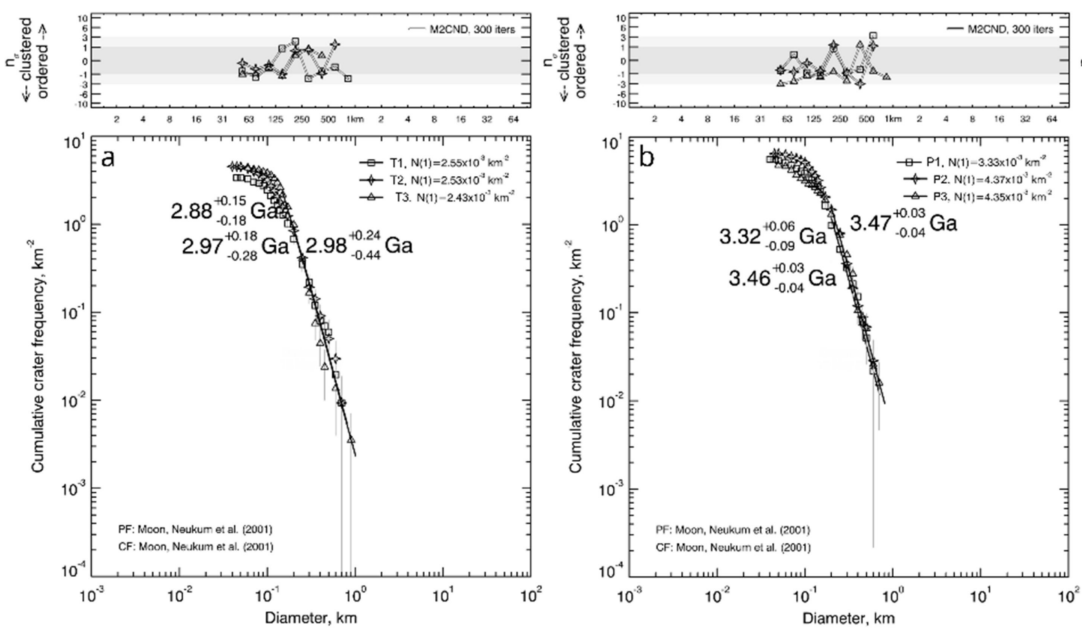
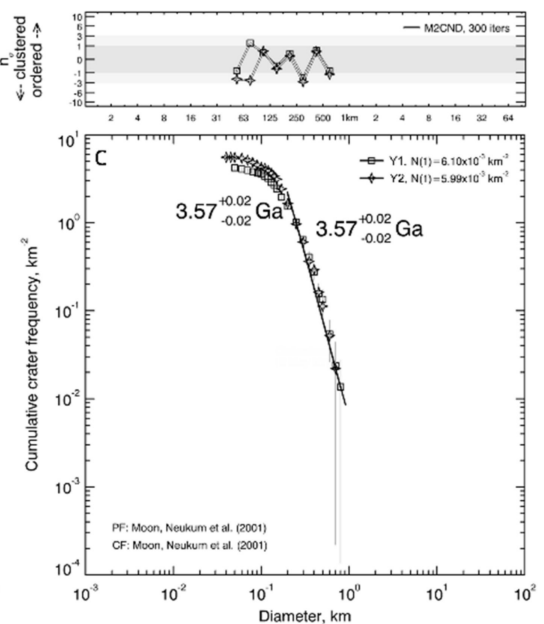

Figure 7. Crater size-frequency distribution (CSFD) measurements performed for areas located on the Tsiolkovskiy crater floor. (a) Age results for the orange color unit (i.e., $b p 1$ unit); (b) age results for the purple-blue color unit (i.e., $b p 2$ unit); and (c) age results for the yellow color unit (i.e., $b p 3$ unit). The randomness analysis results are shown in the panels above the CSFDs.

Here follows the spectral units that have been distinguished associated with unit labels and enlisted in stratigraphic order as suggested by the age determinations.

1. bp1-basaltic plain 1: localized units with higher $750 / 415 \mathrm{~nm}$ (orange) ratio representative of younger events of lava emplacement, not necessarily indicating a change in composition; even if slight differences in composition cannot be excluded, the variation is more likely attributable to a lower degree of maturity due to a shorter exposition to space weathering.

2. $\quad$ bp2-basaltic plain 2: localized units with a higher $415 / 750 \mathrm{~nm}$ (purple-blue) ratio, representative of intermediate events of lava emplacement, older than the $b p 1$ unit and younger than the $b p 3$ unit.

3. bp3-basaltic plain 3: average ratios of $750 / 415 \mathrm{~nm}$ and $750 / 1000 \mathrm{~nm}$ (yellow) indicating a high concentration of weathered mafic minerals, indicative of the spectra of older lava emplacements; brighter hues are due to the excavation of fresher iron-bearing materials due to impacts subsequent to the emplacement of the mare infilling (Figure 8).
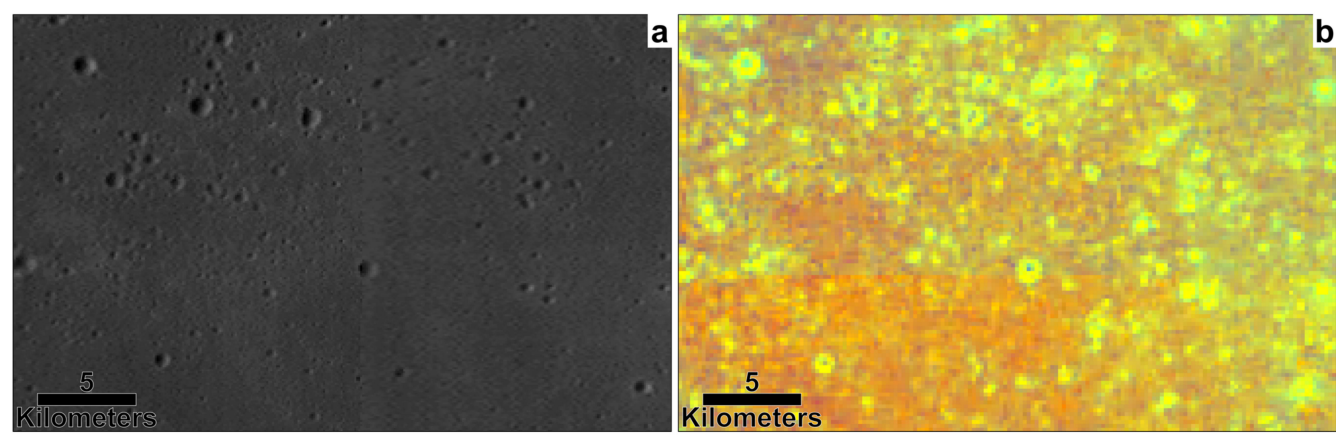

Figure 8. Detailed views from (a) Lunar Reconnaissance Orbiter Wide Angle Camera [30] and (b) Clementine UVVIS Warped Color Ratio [19] mosaics of the Tsiolkovskiy crater floor, highlighting the presence of brighter yellow hues due to the excavation of fresher underlying materials.

4. nt-noritic-anorthosite/troctolite: average $750 / 1000 \mathrm{~nm}$ and $415 / 750 \mathrm{~nm}$ ratios (cyan) indicating lithologies with minor amounts of Fe-bearing minerals such as noritic anorthosite and troctolite [16].

5. an-anorthosite: high $415 / 750 \mathrm{~nm}$ ratio (blue) indicating surfaces with a bright albedo related to a possibly mainly anorthositic composition [16]. 
6. hs - mature and reworked highland soil: high 750/415 $\mathrm{nm}$ ratio (red) indicating highland soil with a high glass content due to the reworking of pre-mare materials and to the maturation of the surface materials, associated with prolonged exposure to space weathering.

The color-based spectral map is shown in Figure 9 on top of the Clementine UVVIS Warped Color Ratio basemap. 


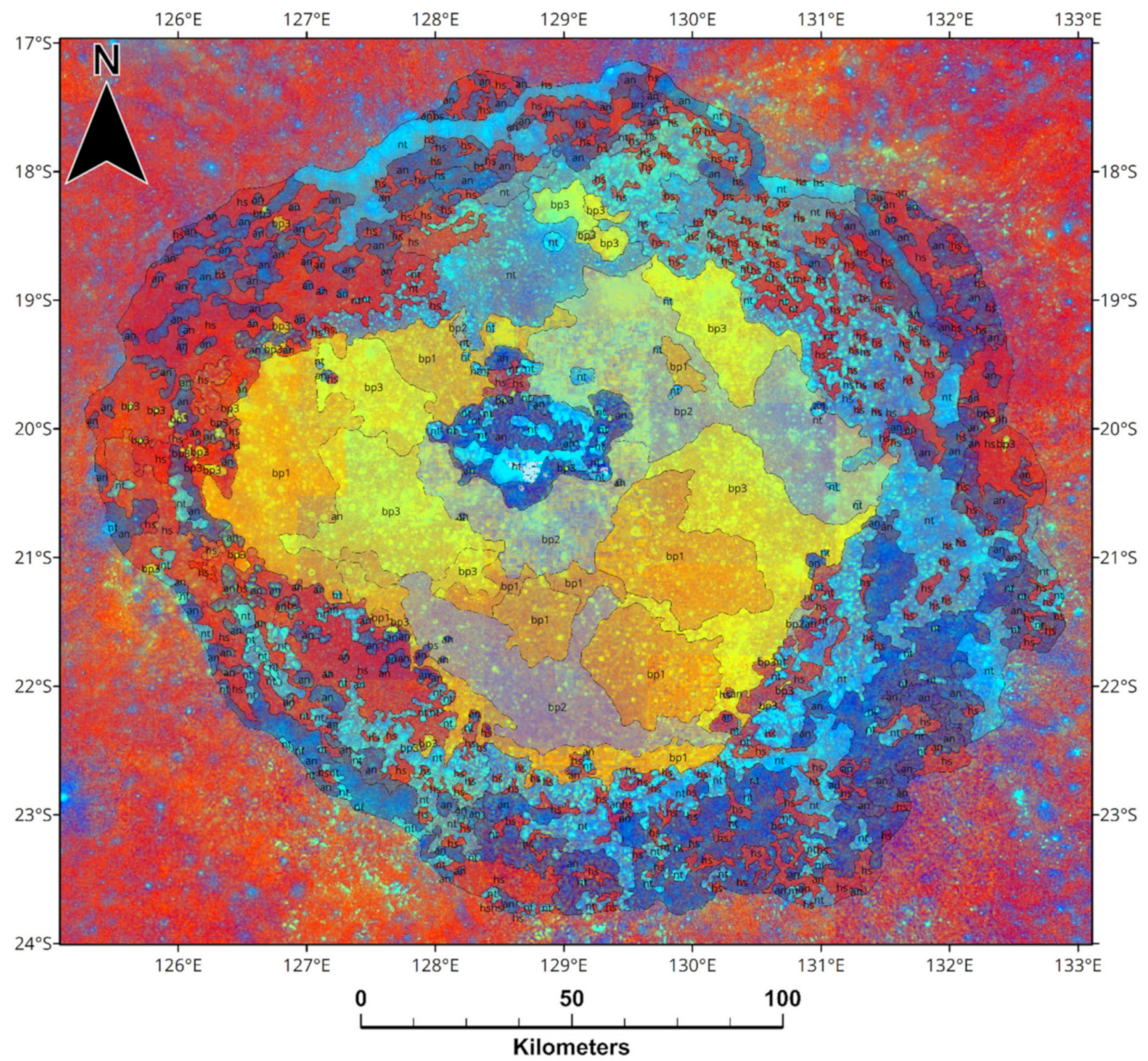

\section{Color-based spectral units}

bp

\section{0 \\ bp2}

Basaltic plain 1

\section{3.}

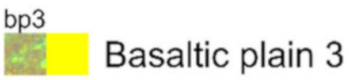

Noritic-anorthosite/troctolite

an

Anorthosite

Mature and reworked highland soil

\section{Spectral contacts}

Contact, certain

---. Contact, approximate

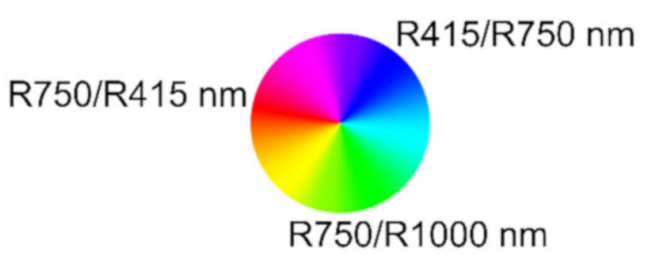

Figure 9. Color-based spectral map of the Tsiolkovskiy crater visualized on top of the Clementine UVVIS Warped Color Ratio mosaic [19]. Refer to the text for unit descriptions. 


\section{Discussion}

The morpho-stratigraphic map presented here constitutes an advance with respect to previous maps $[2-5,12]$ providing a more thorough geologic insight into the Tsiolkovskiy crater. Combined with the unprecedented color-based spectral map, the new map makes it possible to integrate morphological evidence and compositional information. Moreover, the detailed CSFD measurements permit a better understanding of the geologic evolution of this crater, in particular of its lava emplacements.

Even at first glance, it is possible to observe a correlation between the different units identified by the morpho-stratigraphic (Figure 5) and color-based spectral (Figure 9) maps. The most striking feature is the correlation between the sm geologic unit and the $b p 1, b p 2$, and $b p 3$ spectral units attributable to Tsiolkovskiy's crater floor. Conversely, the hummocky material of the $h m$ unit is not as easily ascribable to a spectral color unit. Nonetheless, it can be associated in essence with the same material constituting the $h s$ unit, with exposures from the $n t$ and an units. This is reasonable, given the impact origin of the debris in this unit. The hs spectral unit, moreover, is predominantly correlated with the is unit, and it also includes the scattered $s p$ units, which in the color-based spectral mapping appear homogenized with the surrounding $h s$ unit material. Finally, the fresher deposits exposed by the excavation of the crater ascribed to the $i s, s s$, and $c p$ units are clearly associated with the $n t$ and an spectral units.

Another evident characteristic is that the asymmetric distribution of Tsiolkovskiy's ejecta is not the only asymmetry related to this crater. Indeed, the morpho-stratigraphic map shows that the hummocky material is largely distributed on the western margin of the smooth crater floor relative to the east side. In contrast, the steep scarps and the ponds of smooth material scattered in between the terraces of the rim are more widespread on the SE side of the crater rim than on the NW side.

This is also partially reflected in the irregular distribution of the units identified from the color-based mapping where the NW crater rim is largely made up of the $h s$ unit, while the SE side of the crater rim is mostly made up of the $n t$ and an units.

The peculiar distribution of the units therefore presumably reflects the oblique impact origin of Tsiolkovskiy. The SE inner slope proves to have been more affected by the impact than the NW one. It is indeed characterized by widespread rocky slumps and a larger number of steep scarps that led to the exhumation of greater amounts of $n t$ and an unit materials. Furthermore, even the reduced presence of hummocky patches on the SE portion of the crater floor could be the result of the covering of these areas by larger volumes of effusion generated in the downrange portion of the crater. In the downrange direction of an oblique impact the thickness of crust excavated and mostly affected by the impact is greater than in the uprange direction [41] and references therein. The removal of larger amounts of material and the impact-induced fracturing could have led to an upwelling of lavas in greater quantities with respect to the uprange direction that were nonetheless insufficient to bridge the topographic gap between the NW sector and the SE one.

Finally, the crater counts performed on the $h m$ unit (Figure 2a white polygons) and interpreted as impact melt material returned a formation age of about $3.6 \mathrm{Ga}$, which is in accordance with the results derived by [14] on ejecta and landslide deposits.

The apparent discrepancy of our ages with those obtained by [27-29] lies in the different reference area used for the crater counting. The sum of the ages we derived from the color variegated smooth crater floor (i.e., $b p 1, b p 2$, and $b p 3$ units) returned an average age of $3.28 \mathrm{Ga}$, which is consistent with earlier authors' results of 3.2-3.3 Ga obtained on the same geomorphologic unit.

Nevertheless, the CSFDs we performed on the color units of the mare infilling permit the identification of three different age ranges (i.e., 2.88-2.98 Ga, 3.32-3.47 Ga, and 3.57 Ga) clearly associated with each of the three units (i.e., $b p 1, b p 2$, and $b p 3$ units, respectively) being the result of distinct eruptive events. In saying this, we do not presume that only three lava emplacements took place within Tsiolkovskiy, but that at least three events characterized by distinct compositions and ages are discernible. 
It is noteworthy that there is strong correlation between the different eruptive events and their color variations from the Clementine UVVIS Color Ratio mosaic and the LROCWAC-derived $\mathrm{TiO}_{2}$ abundance estimation basemap by [42] (Figure 10). In particular, the yellow color and the brighter yellow-green hues of the oldest bp3 unit in the Clementine UVVIS Color Ratio mosaic indicate a basaltic unit exposed for a longer time to space weathering and thus characterized by a higher degree of maturity. A bluer Clementine color indicative of higher amounts of titanium characterizes instead the intermediate bp2 unit which shows a $\mathrm{TiO}_{2}$ content of up to $4-6 \mathrm{wt} \%$, while the youngest $b p 1$ unit is characterized by a redder Clementine color, indicative of lower proportions of titanium, with a $\mathrm{TiO}_{2}$ content $<4 \mathrm{wt} \%$.

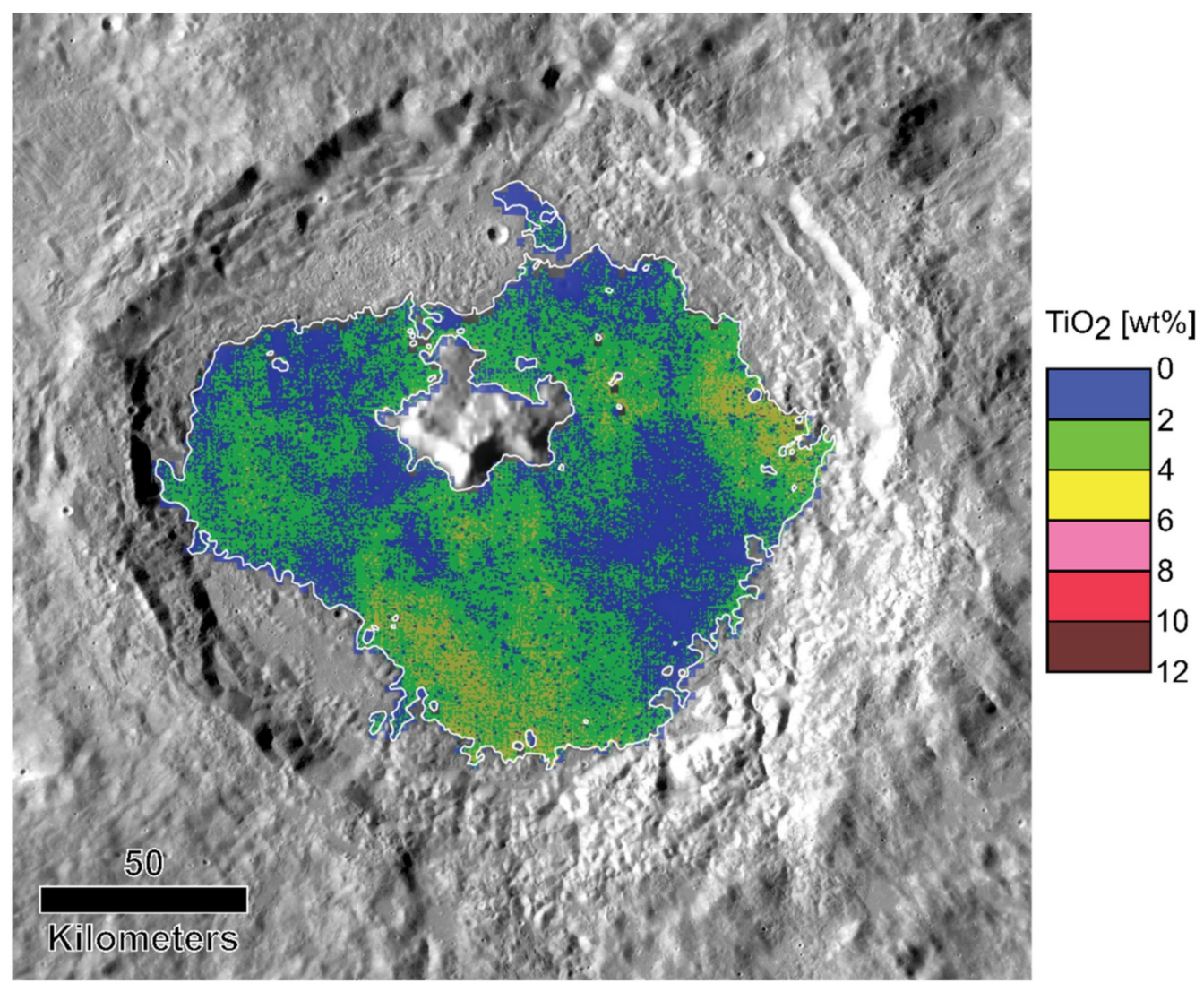

Figure 10. Lunar Reconnaissance Orbiter Wide Angle Camera-derived $\mathrm{TiO}_{2}$ abundance estimation basemap of Tsiolkovskiy's mare infilling, modified from [42]. The color bar indicates $2 \mathrm{wt} \%$ bins in $\mathrm{TiO}_{2}$ content.

This suggests a compositional difference characterizing the flooding events between 3.6 and 3.4 Ga and around 3.0 Ga, probably indicating a shift in lunar far side volcanism. After the first lava emplacements $(\sim 3.6 \mathrm{Ga})$, the production of lavas relatively enriched in titanium content (between 3.6 and $3.4 \mathrm{Ga}$ ) could have been due to (i) the assimilation of $\mathrm{TiO}_{2}$ enriched rocks, (ii) the involvement of a $\mathrm{TiO}_{2}$-enriched plutonic body located at the crustmantle boundary or within the lower crust, or (iii) a distinct magmatic source relatively enriched in titanium content. Subsequently, during the late-stage activity $(\leq 3.0 \mathrm{Ga})$, the lavas underwent a progressive depletion in the proportion of titanium.

Finally, the presence of younger basalts in particular on the south and west margins of the smooth floor could be the result of the load exerted by older lava emplacements that might have forced the new lavas to flow out into lower-pressure zones such as at the margins of the basaltic infilling. 


\section{Conclusions}

A morpho-stratigraphic map of the Tsiolkovskiy crater, coupled with the color-based spectral map and CSFD measurements, permits inferences about its geologic evolution both in terms of compositional variations and the extent of exposure to space weathering of its geological units.

Although the two maps are based on different datasets, it is possible to identify significant correlations between them.

The arrangement of the $\sim 3.6$ Ga old Tsiolkovskiy crater can be summarized as the result of an oblique impact on highland crust. The impact led to the excavation and consequent exhumation of materials unaffected by space weathering, such as norites and anorthosites, that combined with mature highland soil to constitute the crater rim, the uplifted central peak and the hummocky crater floor. The crater floor was then partially filled by a basaltic deposit generated by at least three distinct eruptive events, distinguishable on the basis of their color, composition, and age.

In particular, color-based spectral mapping distinguished three different units for the crater floor, characterized by distinctive Clementine color ratio values (i.e., $b p 1, b p 2$, and $b p 3$ units). The CSFD measurements, performed on three areas for the $b p 1$ and $b p 2$ units and on two areas for the $b p 3$ unit, made it possible to define an approximate time frame for each unit, with average ages of $2.94,3.42$, and $3.57 \mathrm{Ga}$, respectively. These age determinations allowed the reconstruction of the evolutionary history of the crater floor, with the $b p 1$ unit being the youngest basaltic unit, followed by the intermediate $b p 2$ unit, and the oldest $b p 3$ unit. The different compositions of the units, with the $b p 2$ unit presenting the highest proportion of titanium, seem to imply different magma sources and/or suggest melting of $\mathrm{TiO}_{2}$-enriched material at around $3.4 \mathrm{Ga}$.

The oblique impact origin of Tsiolkovskiy is also reflected in the distribution of the units. Relative to the NW uprange portion of the crater, the SE downrange portion presents a greater quantity of excavated material (composing the $n t$ and an units) and rocky slumps and sparse pre-mare material (the $h m$ unit), with the latter probably due to the production of larger effusions in the downrange direction.

In conclusion, the key observations and related implications we provide in this work suggest that the Tsiolkovskiy crater represents a potential site for exploring compositional variability of lavas and magma sources through time on the far side of the Moon, the effects of an oblique impact on the subsequent effusion triggering and emplacement, and lunar lower crust and mantle lithological variability.

Supplementary Materials: The following are available online at http:/ / researchdata.cab.unipd.it/ $\mathrm{id} /$ eprint/513, the ArcGis project with basemaps, the mapping shapefiles, the Spatial Crater Count summary files and an explanatory "README.txt".

Author Contributions: Conceptualization, G.T. and M.M.; methodology, G.T.; formal analysis, G.T., R.P., S.F., and M.M.; resources, G.T.; data curation, G.T.; writing—original draft preparation, G.T.; writing - review and editing, G.T., R.P., M.M., and S.F.; visualization, G.T. and R.P.; supervision, R.P. and M.M.; project administration, M.M.; and funding acquisition, M.M. All authors have read and agreed to the published version of the manuscript.

Funding: This research was supported by the European Union's Horizon 2020 research and innovation program under grant agreement No 871149-GMAP.

Data Availability Statement: The Lunar Reconnaissance Orbiter Wide Angle Camera monochrome mosaic, the Clementine UVVIS Warped Color Ratio mosaic and the Lunar Orbiter Laser Altimeter and Kaguya Terrain Camera Digital Elevation Model are available on the USGS Astrogeology Science Center website (https:/ / astrogeology.usgs.gov/search/ (accessed on 8 September 2021)). The Terrain Camera images are available on the SELENE Data Archive (https://www.darts.isas. jaxa.jp/planet/pdap/selene/product_search.html (accessed on 8 September 2021)). The Lunar Reconnaissance Orbiter Narrow Angle Camera images are available on the PILOT data portal ( https:/ / pilot.wr.usgs.gov/ (accessed on 8 September 2021)). 
Acknowledgments: We are grateful to Simon J. Crowhurst for the revision of the English text. We acknowledge the European Union's Horizon 2020 under grant agreement No 776276-PLANMAP for project collaboration and support.

Conflicts of Interest: The authors declare no conflict of interest.

\section{Appendix A}

Table A1. List of Lunar Reconnaissance Orbiter Narrow Angle Camera (LROC-NAC) [30] images used for the crater size-frequency distribution (CSFD) measurements with relative mean resolution and incidence angle enlisted in ascending resolution order.

\begin{tabular}{|c|c|c|}
\hline LROC-NAC Product ID & $\begin{array}{l}\text { Mean Resolution } \\
\text { (m/pixel) }\end{array}$ & $\begin{array}{c}\text { Incidence Angle } \\
\left({ }^{\circ}\right)\end{array}$ \\
\hline M146140171LE & 0.61 & 67.75 \\
\hline M146140171RE & 0.61 & 67.85 \\
\hline M1107453852LE & 0.88 & 59.16 \\
\hline M103682642RE & 0.88 & 63.33 \\
\hline M103682642LE & 0.89 & 63.19 \\
\hline M165015246LE & 0.91 & 76.05 \\
\hline M165015246RE & 0.91 & 76.14 \\
\hline M192109542LE & 0.92 & 64.30 \\
\hline M192109542RE & 0.93 & 64.45 \\
\hline M1183978587RE & 0.95 & 62.56 \\
\hline M1183978587LE & 0.96 & 62.41 \\
\hline M1174571696LE & 0.96 & 56.82 \\
\hline M1174571696RE & 0.96 & 56.96 \\
\hline M1218112965LE & 1.12 & 78.49 \\
\hline M1218112965RE & 1.12 & 78.61 \\
\hline M1187511756RE & 1.12 & 81.09 \\
\hline M1202818973LE & 1.17 & 81.30 \\
\hline M1202818973RE & 1.17 & 81.42 \\
\hline M1202797929LE & 1.24 & 81.46 \\
\hline M1202797929RE & 1.24 & 81.59 \\
\hline M1125111804LE & 1.30 & 86.44 \\
\hline M1125111804RE & 1.30 & 86.57 \\
\hline M1126296816LE & 1.30 & 81.65 \\
\hline M1126296816RE & 1.30 & 81.78 \\
\hline M180336439LE & 1.32 & 77.85 \\
\hline M180336439RE & 1.32 & 77.98 \\
\hline M1126303929LE & 1.33 & 82.37 \\
\hline M1126303929RE & 1.34 & 82.52 \\
\hline M1141585968LE & 1.34 & 83.28 \\
\hline M1141585968RE & 1.34 & 83.42 \\
\hline M1095658447LE & 1.35 & 79.75 \\
\hline M1095665593LE & 1.41 & 80.39 \\
\hline M1095665593RE & 1.42 & 80.54 \\
\hline M1155723599LE & 1.44 & 86.48 \\
\hline M1233391551RE & 1.44 & 78.10 \\
\hline M1155723599RE & 1.45 & 86.63 \\
\hline M1233391551LE & 1.46 & 77.95 \\
\hline M1155716479RE & 1.53 & 87.27 \\
\hline
\end{tabular}




\section{References}

1. National Research Council. The Scientific Context for Exploration of the Moon; The National Academies Press: Washington, DC, USA, 2007; ISBN 978-0-309-10919-2.

2. Tyrie, A. A description of the crater Tsiolkovsky on the lunar far side. Earth Moon Planets 1988, 42, 265-275. [CrossRef]

3. Gornitz, V. Igneous vs impact processes for the origin of the mare lavas. Moon 1973, 6, 357-379. [CrossRef]

4. Craddock, R.A.; Greeley, R. Thickness and Volume of Mare Deposits in Tsiolkovsky, Lunar Farside. In Proceedings of the 18th Lunar and Planetary Science Conference, The Woodlands, TX, USA, 16-20 March 1987; Lunar and Planetary Institute: Houston, TX, USA, 1988; pp. 331-337.

5. Fortezzo, C.M.; Spudis, P.D.; Harrel, S.L. Release of the digital unified global geologic map of the Moon at 1:5,000,000-scale. In Proceedings of the 51st Lunar and Planetary Science Conference, The Woodlands, TX, USA, 16-20 March 2020; Lunar and Planetary Institute: Houston, TX, USA, 2020; p. 2760.

6. Wilhelms, D.E.; McCauley, J.F. Geologic Map of the Near Side of the Moon; USGS Miscellaneous Investigations Series; USGS Publications Warehouse: Flagstaff, AZ, USA, 1971; Map I-703.

7. Wilhelms, D.E.; El-Baz, F. Geologic Map of the East Side of the Moon; USGS Miscellaneous Investigations Series; USGS Publications Warehouse: Flagstaff, AZ, USA, 1977; Map I-948.

8. Scott, D.H.; McCauley, J.F. Geologic Map of the West Side of the Moon; USGS Miscellaneous Investigations Series; USGS Publications Warehouse: Flagstaff, AZ, USA, 1977; Map I-1034.

9. Stuart-Alexander, D.E. Geologic Map of the Central Far Side of the Moon; USGS Miscellaneous Investigations Series; USGS Publications Warehouse: Flagstaff, AZ, USA, 1978; Map I-1047.

10. Lucchitta, B.K. Geologic Map of the North Side of the Moon; USGS Miscellaneous Investigations Series; USGS Publications Warehouse: Flagstaff, AZ, USA, 1978; Map I-1062.

11. Wilhelms, D.E.; Howard, K.A.; Wilshire, H.G. Geologic Map of the South Side of the Moon; USGS Miscellaneous Investigations Series; USGS Publications Warehouse: Flagstaff, AZ, USA, 1979; Map I-1162.

12. Morse, Z.R.; Osinski, G.R.; Tornabene, L.L.; Neish, C.D. Morphologic mapping and interpretation of ejecta deposits from Tsiolkovskiy crater. Meteorit. Planet. Sci. 2021, 56, 767-793. [CrossRef]

13. Whitford-Stark, J.L. Geologic studies of the lunar far side crater Tsiolkovsky. In Proceedings of the 13th Lunar and Planetary Science Conference, The Woodlands, TX, USA, 15-19 March 1982; Lunar and Planetary Institute: Houston, TX, USA, 1982; pp. 861-862.

14. Boyce, J.M.; Mouginis-Mark, P.; Robinson, M. The Tsiolkovskiy crater landslide, the moon: An LROC view. Icarus 2020, 337, 113464. [CrossRef]

15. Schultz, P.H. Atmospheric effects on ejecta emplacement and crater formation on Venus from Magellan. J. Geophys. Res. 1992, 97, 16183-16248. [CrossRef]

16. Pieters, C.M.; Tompkins, S. Tsiolkovsky crater: A window into crustal processes on the lunar farside. J. Geophys. Res. Planets 1999, 104, 21935-21949. [CrossRef]

17. Wilbur, C.L. Volcano-tectonic history of Tsiolkovskij. In Proceedings of the 9th Lunar and Planetary Science Conference, The Woodlands, TX, USA, 13-17 March 1978; Lunar and Planetary Institute: Houston, TX, USA, 1978; pp. 1253-1254.

18. Mouginis-Mark, P.J.; Boyce, J.M. Mare infilling of Tsiolkovsky crater, the Moon. In Proceedings of the Lunar and Planetary Science XLVIII, The Woodlands, TX, USA, 20-24 March 2017; Lunar and Planetary Institute: Houston, TX, USA, 2017 ; p. 1206.

19. Lucey, P.G.; Blewett, D.T.; Taylor, G.J.; Hawke, B.R. Imaging of lunar surface maturity. J. Geophys. Res. 2000, 105, 20377-20386. [CrossRef]

20. Heather, D.J.; Dunkin, S.K. Crustal stratigraphy of the Al-Khwarizmi-King/Tsiolkovsky-Stark region of the lunar farside as seen by Clementine. Planet Space Sci. 2002, 50, 1311-1321. [CrossRef]

21. Ohtake, M.; Matsunaga, T.; Haruyama, J.; Yokota, Y.; Morota, T.; Honda, C.; Ogawa, Y.; Torii, M.; Miyamoto, H.; Arai, T.; et al. The global distribution of pure anorthosite on the Moon. Nature 2009, 461, 236-240. [CrossRef]

22. Lemelin, M.; Lucey, P.G.; Song, E.; Taylor, G.J. Lunar central peak mineralogy and iron content using the Kaguya Multiband Imager: Reassessment of the compositional structure of the lunar crust. J. Geophys. Res. Planets 2015, 120, 869-887. [CrossRef]

23. Pieters, C.M.; Tompkins, S. Anorthosite and olivine layers of the farside upper crust at Tsiolkovsky. In Proceedings of the 27th Lunar and Planetary Science Conference, The Woodlands, TX, USA, 18-22 March 1996; Lunar and Planetary Institute: Houston, TX, USA, 1996; pp. 1035-1036.

24. Corley, L.M.; McGovern, P.J.; Kramer, G.Y.; Lemelin, M.; Trang, D.; Gillis-Davis, J.J.; Taylor, G.J.; Powell, K.E.; Kiefer, W.S.; Wieczorek, M.; et al. Olivine-bearing lithologies on the Moon: Constraints on origins and transport mechanisms from M3 spectroscopy, radiative transfer modeling, and GRAIL crustal thickness. Icarus 2018, 300, 287-304. [CrossRef]

25. Pieters, C.M.; Tompkins, S.; Staid, M.I.; Fischer, E.M. The low-Ti basalts of Tsiolkovsky as seen by Clementine. In Proceedings of the 26th Lunar and Planetary Science Conference, The Woodlands, TX, USA, 13-17 March 1995; Lunar and Planetary Institute: Houston, TX, USA, 1995; pp. 1121-1122.

26. Wilhelms, D.E. The Geologic History of the Moon, 1st ed.; U.S. Geological Survey Professional Paper; USGS Publications Warehouse: Flagstaff, AZ, USA, 1987; p. 302.

27. Pasckert, J.H.; Hiesinger, H.; van der Bogert, C.H. Small-scale lunar farside volcanism. Icarus 2015, 257, 336-354. [CrossRef] 
28. Williams, J.-P.; Petro, N.E.; Greenhagen, B.T.; Neish, C. Inferred age of mare fill in Tsiolkovskiy crater: Constraints on the preservation of exterior impact melt deposits. In Proceedings of the 44th Lunar and Planetary Science Conference, The Woodlands, TX, USA, 18-22 March 2013; Lunar and Planetary Institute: Houston, TX, USA, 2013; p. 2756.

29. Greenhagen, B.T.; Neish, C.D.; Williams, J.-P.; Cahill, J.T.S.; Ghent, R.R.; Hayne, P.O.; Lawrence, S.J.; Petro, N.E.; Bandfield, J.L. Origin of the anomalously rocky appearance of Tsiolkovskiy crater. Icarus 2016, 273, 237-247. [CrossRef]

30. Robinson, M.S.; Brylow, S.M.; Tschimmel, M.; Humm, D.; Lawrence, S.J.; Thomas, P.C.; Denevi, B.W.; Bowman-Cisneros, E.; Zerr, J.; Ravine, M.A.; et al. Lunar reconnaissance orbiter camera (LROC) instrument overview. Space Sci. Rev. 2010, 150, 81-124. [CrossRef]

31. Haruyama, J.; Matsunaga, T.; Ohtake, M.; Morota, T.; Honda, C.; Yokota, Y.; Torii, M.; Ogawa, Y. Global lunar-surface mapping experiment using the Lunar Imager/Spectrometer on SELENE. Earth Planets Sp. 2008, 60, 243-255. [CrossRef]

32. Smith, D.E.; Zuber, M.T.; Jackson, G.B.; Cavanaugh, J.F.; Neumann, G.A.; Riris, H.; Sun, X.; Zellar, R.S.; Coltharp, C.; Connelly, J.; et al. The lunar orbiter laser altimeter investigation on the lunar reconnaissance orbiter mission. Space Sci. Rev. 2010, 150, $209-241$. [CrossRef]

33. Barker, M.K.; Mazarico, E.; Neumann, G.A.; Zuber, M.T.; Haruyama, J.; Smith, D.E. A new lunar digital elevation model from the Lunar Orbiter Laser Altimeter and SELENE Terrain Camera. Icarus 2016, 273, 346-355. [CrossRef]

34. Tobler, W. Measuring spatial resolution. In Proceedings of the Land Resources Information Systems Conference, 1987. pp. 12-16. Available online: https:/ / www.researchgate.net/profile/Waldo-Tobler/publication/291877360_Measuring_spatial_resolution/ links/595ef94ba6fdccc9b17fe8ee/Measuring-spatial-resolution.pdf (accessed on 30 August 2021).

35. Tanaka, K.L.; Skinner, J.A.; Hare, T.M. Planetary Geologic Mappers Handbook; USGS Astrogeology Science Center: Flagstaff, AZ, USA, 2011; p. 24.

36. Kneissl, T.; van Gasselt, S.; Neukum, G. Map-projection-independent crater size-frequency determination in GIS environmentsNew software tool for ArcGIS. Planet. Space Sci. 2011, 59, 1243-1254. [CrossRef]

37. Michael, G.G.; Neukum, G. Planetary surface dating from crater size-frequency distribution measurements: Partial resurfacing events and statistical age uncertainty. Earth Planet. Sci. Lett. 2010, 294, 223-229. [CrossRef]

38. Michael, G.G.; Kneissl, T.; Neesemann, A. Planetary surface dating from crater size-frequency distribution measurements: Poisson timing analysis. Icarus 2016, 277, 279-285. [CrossRef]

39. Neukum, G.; Ivanov, B.A.; Hartmann, W.K. Cratering records in the inner solar system in relation to the lunar reference system. Space Sci. Rev. 2001, 96, 55-86. [CrossRef]

40. Michael, G.G.; Platz, T.; Kneissl, T.; Schmedemann, N. Planetary surface dating from crater size-frequency distribution measurements: Spatial randomness and clustering. Icarus 2012, 218, 169-177. [CrossRef]

41. Pierazzo, E.; Melosh, H.J. Understanding oblique impacts from experiments, observations, and modeling. Annu. Rev. Earth Planet Sci. 2000, 28, 141-167. [CrossRef] [PubMed]

42. Sato, H.; Robinson, M.S.; Lawrence, S.J.; Denevi, B.W.; Hapke, B.; Jolliff, B.L.; Hiesinger, H. Lunar mare TiO 2 abundances estimated from UV/Vis reflectance. Icarus 2017, 296, 216-238. [CrossRef] 